\title{
LESÃO DE PARAGÂNGLIO INTERATRIAL EM CHAGÁSICO CRÔNICO. APRESENTAÇÃO DE UM CASO.
}

\author{
Helenice Gobbi, Paula D'Avila Fernandes, Vicente de Paula Antunes Teixeira e \\ Hipólito de Oliveira Almeida.
}

Embora descritos no coração de alguns mamife$\operatorname{ros}^{4} 912$, os paragânglios cardíacos do homem adulto não têm sido objeto de estudos anatômicos. É provável que isto se deva à crença existente até há poucos anos de que no homem o sistema cromafim extra-adrenal regredia após o nascimento. Entretanto Friedman e Goldman ${ }^{3}$, Hernoven e cols 56 , Kuo e cols ${ }^{7}$, Leesma e Pride $^{8}$ demonstraram que os paragânglios abdominais persistem no homem adulto. Recentemente, iniciamos estudos que nos levaram a localizar parte deste sistema na gordura interatrial do coração humano adulto1. Tendo a oportunidade de analisar um destes paragânglios no coração de chagásico crônico, achamos oportuno divulgar o fato para despertar maior interesse sobre o assunto.

\section{APRESENTAÇĀO DO CASO}

JRR, 73 anos, lavrador, natural e residente em Rio Paranaiba (MG). Paciente internado com queixa gástrica, vindo a falecer de modo súbito após crise de agitação e dispnéia.

A necropsia revelou úlcera péptica na pequena curvatura da região pilórica, com exposição e corrosão da parede de pequena artéria. Abundante quantidade de sangue coagulado, no estômago e intestino. $O$ coração pesava $360 \mathrm{~g}$ e apresentava espessamentos leitosos do epicárdio (em placas nos átrios e ventriculos e em pequenos nódulos ao longo de ramos da artéria descendente anterior) e lesão vorticilar esquerda (lesão da ponta) de $2 \mathrm{~cm}$ de diâmetro. $O$ exame microscópico revelou miocardite focal, caracterizada principalmente por exsudato mononuclear. $O$ exame de cortes seriados do terço superior do septo interatrial mostrou um paragânglio que apresentava exsudato mononuclear, constituido principalmente por células tipo pequeno linfócito. $\mathrm{Na}$ região do infiltrado as células paragangliais aparentemente foram destruídas (Figuras 1 e 2).

Disciplina de Patologia Geral da Faculdade de Medicina do Triângulo Mineiro - 38100 - Uberaba-MG - Brasil.

Recebido para publicação em 8/10/84.

\section{DISCUSSÃO}

O presente caso é de um chagásico aparentemente assintomático (provável forma indeterminada da doença) que faleceu em conseqüência de hemorragia digestiva por úlcera péptica. Como o paciente não foi estudado sob o ponto de vista cardiológico, não será possivel nenhuma tentativa de correlação anatomoclínica. Entretanto, o simples fato de se registrarem alterações inflamatórias em paragânglio cardiaco de paciente tripanossomótico contribui para despertar interesse pelo assunto.

Os paragànglios atriais, tendo a mesma origem embriológica e mesmo uma certa semelhança morfofuncional com o sistema nervoso autônomo, parecem também vulneráveis à ação patogênica do $T$. cruzi, a julgar pelos nossos achados. Aliás, a medular das supra-renais, que é também um paragânglio, mostra-se igualmente lesada no chagásico crônico ${ }^{15}$.

O paragânglio atrial do caso estudado mostrava áreas de aparente desaparecimento das células paragangliais e infiltrado mononuclear constituido principalmente por linfócitos. Este exsudato não é propagação da epicardite, mas atinge primariamente o paragânglio, uma vez que a gordura em torno não exibe sinais inflamatórios. Observação semelhante fizemos para os gânglios e nervos intracardiacos de chagásicos crônicos $^{2}$. Teixeira ${ }^{13}$ e Teixeira e cols ${ }^{14}$ admitem que antigenicidade cruzada do $T$. cruzi com o miocárdio e gânglios nervosos seria fator básico para explicar tanto a agressão miocárdica como as lesões do sistema nervoso autônomo.

Pode-se também admitir que as células cromafins dos paragânglios atriais e os neurônios do sistema nervoso autônomo teriam antigenos comuns, entre os quais estaria o responsável pela antigenicidade cruzada com o T. cruzi. Entretanto, Ribeiro dos Santos e cols 10 admitem que os anticorpos antineurônios e antinervo, que surgem nos chagásicos crônicos, seriam mais conseqüência que causa de agressão nervosa. Ribeiro dos Santos e Hudson 11 descrevem adsorção dos antigenos parasitários à superficie de células nervosas e musculares, sendo a agressão imunitária e 


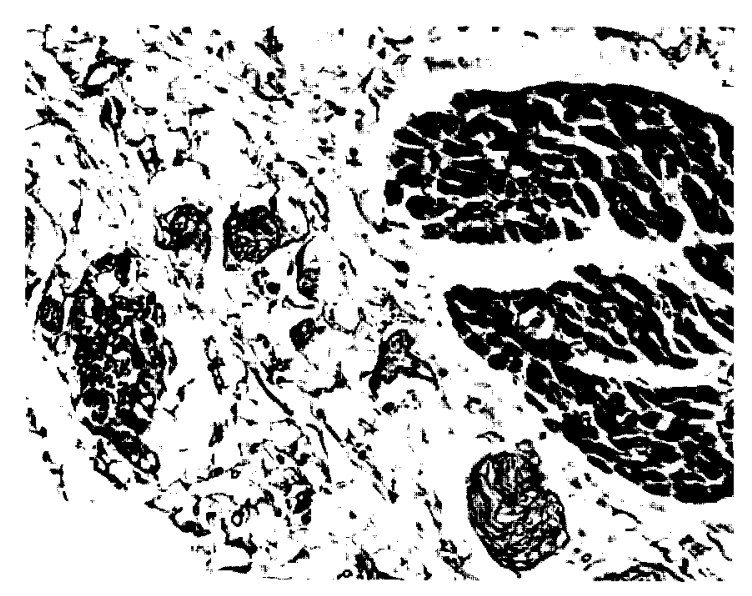

Figura 1 - Paragânglio interatrial (embaixo à esquerda) próximo a pequenos filetes nervosos. Mesmo no pequeno aumento pode-se observar $o$ infiltrado mononuclear. À direita, feixe muscular do septo interatrial. HE $63 \mathrm{x}$.

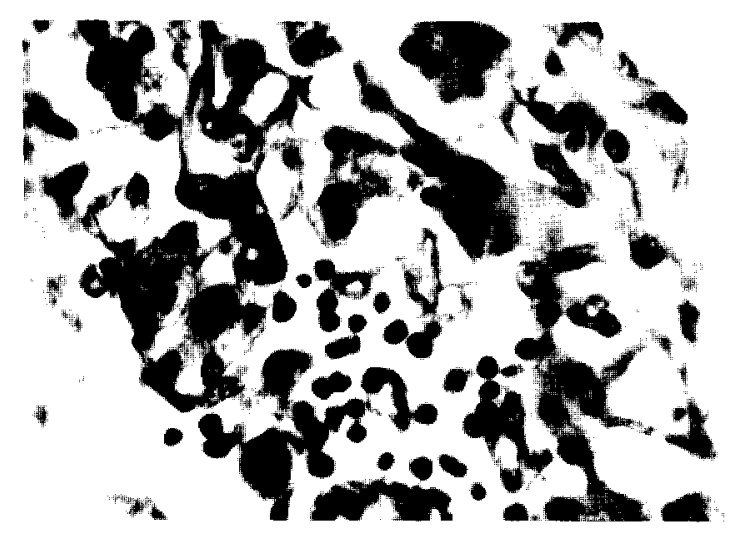

Figura 2 - Detalhe da figura anterior. As células paragangliais mostram citoplasma granuloso e abundante. $\mathrm{O}$ exsudato mononuclear acumula-se na intimidade do paragânglio, onde faltam células cromafins. HE $160 x$.

as lesões nervosas e miocárdicas decorrentes desta adsorção antigênica.

Não temos elementos para analisar as conseqüências funcionais da lesão paraganglial, uma vez que seu papel na fisiologia cardíaca é desconhecido. Entretanto, admite-se que os paragânglios atriais atuariam modulando e regulando a atividade dos gânglios nervosos ${ }^{12}$. Desta forma, a lesão paraganglial poderia levar a uma desestabilização da atividade dos gânglios cardíacos que são também lesados nos chagásicos.

\section{REFERÊNCIAS BIBLIOGRÁFICAS}

1. Almeida HO, Gobbi H, Teixeira VPA, Brandão MC. Paragânglio interatrial no coração humano adulto. Arquivos Brasileiros de Cardiologia. Enviado para publicação, 1984.

2. Almeida HO, Teixeira VPA, Gobbi H, Araujo WF. Alteraçōes qualitativas do sistema nervoso autônomo intracardíaco (SNAIC) em chagásicos crônicos. Arquivos Brasileiros de Cardiologia 41: 171-174, 1983.

3. Friedman M, Goldman RL. Paraganglia in the human prostate. Journal of Urology 113: 874-875, 1975.

4. Goormaghtigh N, Painnier R. Les paraganglions du coeur et des zones vasosensibles carotidiene et aorticopulmonares chez le chat adult. Archives Biologie (Paris) 50: 455-533, 1930.

5. Hernoven A, Vaalasti A, Partanen M, Kanerva L, Vaalasti T. The paraganglia: a persisting endocrine system in man. American Journal of Anatomy 146: $207-$ 210,1976 .

6. Hernoven A, Partanen S, Vaalasti A, Partanen M, Kanerva L, Alho H. The distribution and endocrine nature of the abdominal paraganglia of adult man. American Journal of Anatomy 153: 563-572, 1978.

7. Kuo T, Anderson CB, Rosai J. Normal paraganglia in the human gall bladder. Archives of Pathology 97: 46-47, 1974.

8. Leesma JE, Pride EP. Paraganglioma of the urinary bladder. Cancer 28: 1064-1068, 1971.

9. Muratori G. Distribuizione e caracteristiche istomorfologiche dei paragangli atriali del cuore del gato. Archivio Italiano Anatomia Embriologia 74: 1-13, 1969.

10. Ribeiro dos Santos R, Marquez JO, Von Gal Furtado CC, Ramos de Oliveira JC, Martins AR, Köberle F. Antibodies against neurons in chronic Chagas' disease. Tropenmedizin und Parasittologie 30: 19-22, 1979.

11. Ribeiro dos Santos R, Hudson L. Trypanosoma cruzi: adsorption of parasite antigens to mammalian cell surfaces. Parasite Immunology 2: 1-10, 1980.

12. Tafuri WL, Cunha-Melo JR, Freire-Maia L. Ultrastructure and possible function of an atrial paraganglion not directly related to atrial ganglion in the albino mouse. Journal of Neural Transmission 44: 333-338, 1979. 
Gobbi H, Fernandes PA, Teixeira VPA, Almeida HO. Lesão de paragânglio interatrial em chagásico crónico. Apresentação de um caso. Revista da Sociedade Brasileira de Medicina Tropical 18: 113-115, Abr-Jun, 1985

13. Teixeira ARL. Competência imunológica do paciente chagásico - Imunodepressão na forma aguda inaparente, auto-imunidade no hospedeiro humano. Tese Faculdade Ciências da Saúde da Universidade de Brasilia, Brasilia, 1979.

14. Teixeira ARL, Teixeira ML, Santos Buch CA. The immunology of experimental Chagas' disease. IV The production of lesions in rabbits similar to those of chronic Chagas' disease in man. American Journal of Pathology 80: $163-180,1975$.

15. Teixeira VPA, Gobbi H, Almeida HO. Andrenalite em chagásicos crónicos. Revista da Sociedade Brasileira de Medicina Tropical, 1984 in press. 